\title{
Technical Evaluation of Mechanical Recycling of PLA 3D Printing Wastes ${ }^{\dagger}$
}

\author{
Eduardo Moreno 1, Freddys R. Beltrán 1,2, , Marina Arrieta 1,2, Gerald Gaspar 1, \\ María L. Martínez Muneta ${ }^{1}$, Ruth Carrasco-Gallego ${ }^{1}$, Susana Yañez ${ }^{1}$, David Hidalgo ${ }^{1}$, \\ María U. de la Orden ${ }^{2,3}$ and Joaquín Martínez Urreaga ${ }^{1,2}$ \\ 1 Escuela Técnica Superior de Ingenieros Industriales, Universidad Politécnica de Madrid, Madrid, Spain; \\ eduardo.moreno.escribano@gmail.com (E.M.); m.arrieta@upm.es (M.A.); \\ geraldmanuel.gaspar@upm.es (G.G.); luisa.mtzmuneta@upm.es (M.L.M.M.); \\ ruth.carrasco@upm.es (R.C.-G.); susana.yanez@upm.es (S.Y.); \\ david.hidalgo.carvajal@alumnos.upm.es (D.H.); joaquin.martinez@upm.es (J.M.U.) \\ 2 Grupo de Investigación Polímeros Caracterización y Aplicaciones, Universidad Politécnica de Madrid, \\ Madrid, Spain; mariula@quim.ucm.es \\ 3 Facultad de Óptica y Optometría, Universidad Complutense de Madrid, Madrid, Spain \\ * Correspondence: f.beltran@upm.es; Tel.: +34-910-677-295 \\ + Presented at the First International Conference on “Green” Polymer Materials 2020, 5-25 November 2020; \\ Available online: https://cgpm2020.sciforum.net/.
}

Published: 4 November 2020

\begin{abstract}
The importance of 3D printing is growing rapidly. A recent example is the fight against the Covid-19 pandemic, in which 3D printing has helped to overcome the shortage of critical supplies. However, 3D printing generates large amounts of plastic waste that could pose an environmental problem, thus making necessary to find methods for the correct management of such wastes. The combination of additive manufacturing and distributed mechanical recycling can contribute to the development of a more circular economy. The main goals of this work were to characterize the PLA wastes generated in 3D printing processes and evaluate the effect of their heterogeneity on the technical feasibility of mechanical recycling. Two PLA 3D printing wastes were used: waste coming from a well-known PLA grade, and a mixture of PLA 3D printing residues coming from an association of coronamakers in Madrid. Recycled material obtained from waste of a wellknown PLA grade shows good properties, similar to non-used material. However, the recycled material obtained from mixed PLA waste shows lower viscosity values, higher crystallization ability and less transparency. These results highlight that special attention should be paid to the sorting and characterization of the 3D wastes, to obtain recycled materials with good properties.
\end{abstract}

Keywords: poly(lactic acid); 3D printing; mechanical recycling; plastic waste; circular economy

\section{Introduction}

$3 \mathrm{D}$ printing is an additive manufacturing technique that is gaining a fair amount of interest in recent years due to its relatively low cost and simplicity. Industries such as construction, automotive, medical, aerospace and energy among others are driving the market of 3D printing, to the point that a $23 \%$ market growth was expected by $2021[1,2]$. The relevance of 3D printing as manufacturing technique increased even more during the worldwide COVID-19 pandemic. The versatility, quick prototyping and worldwide availability of designs allowed to mitigate the shortage of critical supplies in the fight against the pandemic. Among those critical suppliers are personal protective equipment (PPEs), medical devices and testing devices [3]. Several iniatitives, such as coronamakers (Spain), produced large amounts of face shields and other accessories using poly(lactic acid) (PLA) 
as their main material, which is one of the most used plastics in 3D printing applications, due to its renewable origin, good properties and commercial availability [4]. However, 3D printing generates a large amount of plastic waste, coming from scrap, failed prints and defective pieces. Therefore, to assure the sustainability of 3D printing it is necessary to propose methods to manage the increasing amount of plastic waste generated. One of the most interesting alternatives is the mechanical recycling of the plastic waste, since it allows to reduce raw materials and energy consumption, as well as emissions related to the manufacture of the virgin polymers [5].

Despite the potential advantages of mechanical recycling of 3D printing wastes, only a very small fraction of PLA waste is currently recycled [6]. The destination of the vast majority of 3D printing waste is landfill. In order to explain this fact, a well-known barrier to the mechanical recycling of PLA 3D printing waste is the degradation suffered by the polymer during the recycling process, which results in chain scission that leads to a decrease of the average molecular weight and, consequently, of some mechanical and thermal properties [6,7]. This result is in good agreement with other studies related to the mechanical recycling of PLA waste from other applications [8,9]. Peeters et al. have analyzed other barriers that hinder the mechanical recycling of PLA 3D printing waste. Their results have shown that other important barriers are the use of different grades of the polymer and the lack of knowledge of the properties of the residues [10].

Therefore, the main objective of this work was to evaluate the effects of the heterogeneity of 3D printing PLA residues on the properties of the recycled material. Two very different residues were collected, characterized and then recycled. One of them came from a pure well-known PLA grade, printed in controlled conditions. The other waste is a mixture of PLA waste generated by different users that are part of a group of coronamakers in Madrid (Spain) and were generated during the Covid-19 pandemic. The characterization of this waste mix showed the presence of different degrees of PLA and the absence of significant contamination from other plastics. No information was available on the conditions under which these mixed wastes were produced. The main results suggest that special care must be paid to the selection and characterization of the PLA 3D printing waste, since heterogeinity could lead to materials with lower viscosity, different crystallization behavior and visual appearance and lower thermal properties.

\section{Experiments}

\subsection{Materials}

Two PLA wastes were used in this study. One of them consisted on PLA 3D printing wastes coming from a single well-known grade, commercially available with the name of Smartfil ${ }^{\circledR}$ PLA (Smart Materials 3D). The second waste consisted of a mixture of PLA 3D printing wastes coming from an association of coronamakers of Madrid (Spain). The non-used Smartfil ${ }^{\circledR}$ PLA filament was also used to obtain a reference material.

\subsection{D Printing Conditions of the Reference Grade}

Waste coming from Smartfil ${ }^{\circledR}$ PLA were printed at room temperature $\left(23-25^{\circ} \mathrm{C}\right)$ in a ABAX PRI5 3D printer operating at $200^{\circ} \mathrm{C}$.

\subsection{Mechanical Recycling of the Materials}

All the PLA 3D-printing wastes were subjected to an energic washing process, similar to that used in industrial conditions $[8,11]$, at $85{ }^{\circ} \mathrm{C}$ using a $1 \%$ wt. $\mathrm{NaOH}$ and $0.3 \% w t$. surfactant solution. After the whasing step, all materials were carefully dried under vacuum.

Mechanical recycling of the 3D printing wastes was conducted in a Rondol Microlab twin-screw microcompounder with a $\mathrm{L} / \mathrm{D}$ ratio of 20 , using a rotation speed of $60 \mathrm{rpm}$. The temperature profile, from hopper to die was $125,160,190,190$ and $180^{\circ} \mathrm{C}$. After extrusion, the samples were turned into films, with a thickness of $200 \pm 10 \mu \mathrm{m}$, using a hot-plate press (IQAP-LAP) at $190^{\circ} \mathrm{C}$. A sample of the non-used (virgin) PLA filament was also processd in order to be used as reference material. The studied materials are summarized in Table 1. 
Table 1. Description of the obtained materials.

\begin{tabular}{cc}
\hline Sample & Description \\
\hline PLA-f & Non-used PLA 3D filament (Smartfil ${ }^{\circledR}$ PLA) \\
Ref-3D-PLA & PLA-f subjected to printing at controlled conditions \\
3D-PLA-R & 3D printing wastes coming from PLA-f, subjected to mechanical recycling \\
Cor-PLA-w-R & 3D printing wastes coming from the coronamakers association, subjected \\
& to mechanical recycling \\
\hline
\end{tabular}

\subsection{Characterization Techniques}

Intrinsic viscosity measurements of the samples were performed using an Ubbelohde viscometer at $25^{\circ} \mathrm{C}$, using chloroform as a solvent. Each sample was measured at four different concentrations.

DSC scans were performed in a TA Instruments Q20 calorimeter, using aluminum pans, samples of $5 \mathrm{mg}$ and a $50 \mathrm{~mL} / \mathrm{min}$ nitrogen flowrate. The samples were subjected to the following protocol: a first heating scan from 30 to $180^{\circ} \mathrm{C}$, at $5^{\circ} \mathrm{C} / \mathrm{min}$; a three minute isothermal step at $180{ }^{\circ} \mathrm{C}$; a cooling scan from 180 to $0{ }^{\circ} \mathrm{C}$ at $5{ }^{\circ} \mathrm{C} / \mathrm{min}$; an one minute isothermal step at $0{ }^{\circ} \mathrm{C}$; and a second heating from 0 to $180^{\circ} \mathrm{C}$ at $5^{\circ} \mathrm{C} / \mathrm{min}$.

TGA tests were conducted in a TA Instruments TGA 2050 thermobalance, under nitrogen atmosphere $(30 \mathrm{~mL} / \mathrm{min})$, using samples of $10 \mathrm{mg}$ and platinum pans. The samples were heated from 40 to $800{ }^{\circ} \mathrm{C}$ at $10^{\circ} \mathrm{C} / \mathrm{min}$.

\section{Results and Discussion}

\subsection{Intrinsic Viscosity}

PLA is susceptible to undergo degradation reactions when is subjected to high temperatures and shear stresses, as those present during 3D-printing and other melt extrusion processes. Mechanisms like hydrolysis, oxidative degradation and intermolecular transesterification are responsible for the decrease of the average molecular weight, and intrinsic viscosity, of PLA during melt processing [12]. Furthermore, intrinsic viscosity is a fundamental parameter in the melt processing of polymers, since some processes and equipment are designed to operate at specific intrinsic viscosity conditions. Therefore, it is very important to analyze the effect of the 3D printing process and of the mechanical recycling on the intrinsic viscosity of PLA, in order to quantify the degradation of the polymer during both processes. Obtained results are summarized in Figure 1.

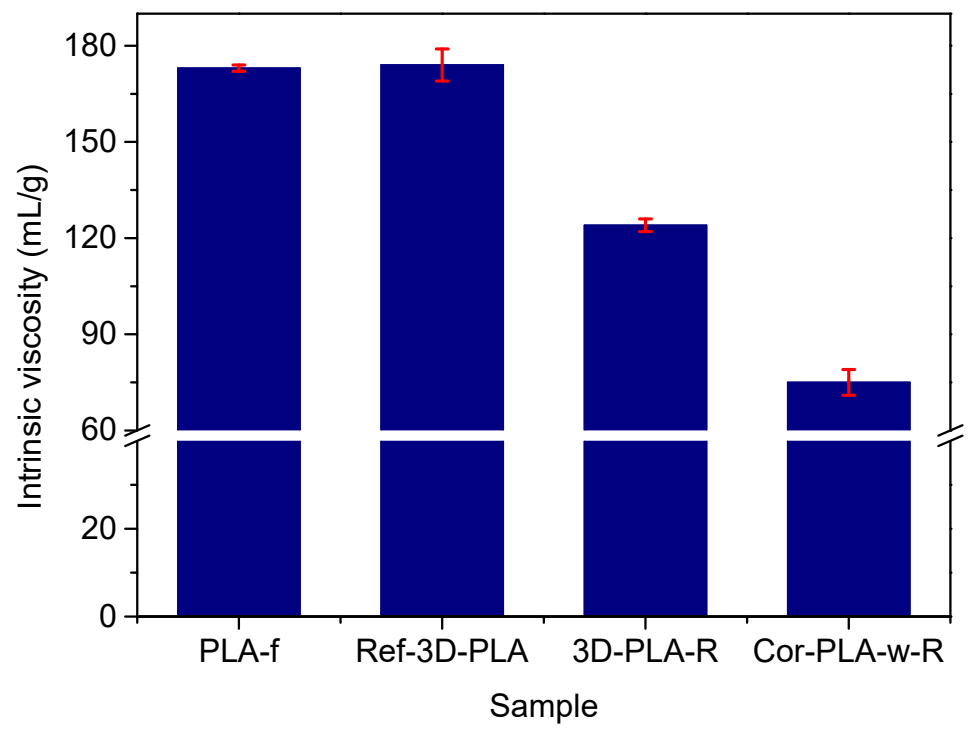

Figure 1. Intrinsic viscosity values of the different materials. 
It can be seen on Figure 1 that 3D printing process, under the conditions used in this work, did not severely degrade PLA, since the intrinsic viscosity values of PLA-f and Ref-3D-PLA are very similar. However, the washing and the melt reprocessing led to an, approximately, 29\% decrease of the intrinsic viscosity of the material. This behavior is in good agreement with previous studies focused on the mechanical recycling of PLA, which pointed out that the washing process could weaken the structure of the material and generate terminal $-\mathrm{COOH}$ and $-\mathrm{OH}$ groups. These terminal groups could catalyze the thermomechanical degradation during the melt reprocessing step $[8,13]$. It is also worth to note that the recycled blend of the coronamakers waste materials presents the lowest intrinsic viscosity value of all the samples. This result might be explained by the different processing conditions, PLA grades and degradation levels that the coronamakers wastes might have, which result in a blend with a lower intrinsic viscosity value. This behavior highlights one of the main technical barriers of mechanical recycling, which is the heterogeneity of the materials and its negative effects on the over performance of the recycled products limiting their industrial explotation.

\subsection{Thermal Properties}

Washing and reprocessing steps, along with the origin of the materials, greatly affects the intrinsic viscosity of the recycled materials as it shown on Figure 1. Therefore, it could be expected some properties of the recycled samples to change as a result of the degradation. Among these properties are thermal behavior and thermal stability, which were measured by DSC and TGA, respectively. The most relevant results are presented on Table 2.

Table 2. Thermal parameters of the samples obtained by DSC (cooling scan) and TGA.

\begin{tabular}{cccc}
\hline Sample & $\mathrm{T}_{\text {crist }}\left({ }^{\circ} \mathrm{C}\right)$ & $\Delta \mathrm{H}_{\text {crist }}(\mathrm{J} / \mathrm{g})$ & $\mathrm{T}_{10}\left({ }^{\circ} \mathrm{C}\right)$ \\
\hline PLA-f & 92.3 & 1 & 315.2 \\
Ref-3D-PLA & 94.3 & 1 & 313.1 \\
3D-PLA-R & 94.1 & 1 & 314.7 \\
Cor-PLA-w-R & 105.3 & 21 & 299.7 \\
\hline
\end{tabular}

The DSC results, obtained from the cooling scan, point out that the recyclate coming from a well known single PLA grade shows a behavior very similar to that of the virgin (reference) material. The low crystallization enthalpy values are characteristic of PLA grades with low crystallization ability. These low values are found even in the 3D-PLA-R sample, which presented an important decrease of the intrinsic viscosity. However, the recycled material obtained from the mixed waste of the coronamakers shows an increase of the crystallization temperature and an important crystallization peak. This behavior is in good agreement with intrinsic viscosity values, since the shorter polymer chains cristallyze more easily. Furthermore, this strong crystallization might suggest that the coronamakers wastes are composed of PLA grades designed to have good crystallization behavior, probably by using nucleating agents.

Regarding the thermal stability of the samples, Table 2 presents the $T_{10}$ values, which is the temperature at which $10 \%$ of the mass is lost, and is commonly used as an indicator of thermal stability. On the one hand, it can be seen that 3D printing in controlled conditions does not siginifcantly affect the thermal stability of PLA, since the T10 values of PLA-f and Ref-3D-PLA are very close between each other, even after the recycling process (Ref-3D-PLA). On the other hand, it can be seen that the recyclate obtained from the mixed waste show a lower thermal stability, which is in good agreement with the intrinsic viscosity values, since shorter polymer chains are removed at lower temperatures $[8,14]$.

\subsection{Visual Properties}

In the field of 3D printing manufacturing, the visual aspect of the obtained products plays a very important role in the potential demand of the printing materials. Figure 2 shows the visual aspect of the different materials. On the one hand, it can be seen that all the samples coming from the well 
known PLA grade show a similar aspect. On the other hand the Cor-PLA-w-R sample presents a totally different color and less transparency than the other samples, which could be attributed to the presence of different colored materials in the 3D printing wastes.

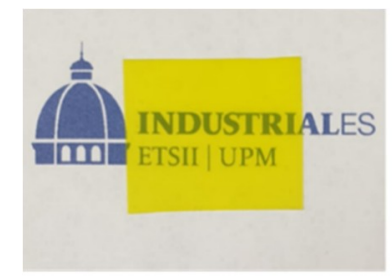

PLA-f

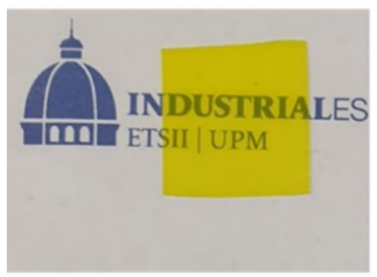

3D-PLA-R

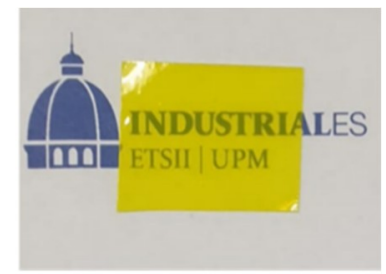

Ref-3D-PLA

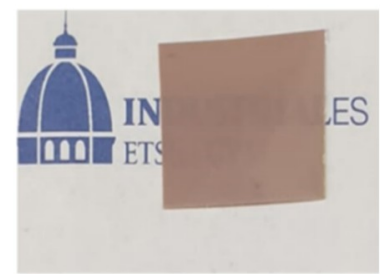

Cor-PLA-w-R

Figure 2. Visual appearance of the different films samples.

\section{Conclusions}

The technical viability of the mechanical recycling of homogeneous and heterogeneous PLA 3D printing wastes was studied. The effect of a energic washing process and a melt reprocessing step was determined on two different samples: (i) a PLA 3D printing waste coming from a single well known PLA filament and (ii) a mixed PLA 3D printing waste coming from different PLA grades, kindly supplied by a coronamakers association. Intrinsic visocisy measurements suggest that $3 \mathrm{D}$ printing process does not severely degrade the material, but thewashing and reprocessing steps led to an important degradation. Furthermore, the intrinsic viscosity values of the recyclate coming from the mixed waste was low, which might be problematic when determining processing conditions for the recycled material. Regarding the properties of the materials, the thermal analysis results point out that the recycled PLA crystallyzes more easily than the sample recycled from a single PLA grade.

Overall, the results suggest that mechanical recycling of 3D printing PLA wastes is feasible, from a material properties point of view. However, special attention should be paid to the origin and composition of the wastes, since hetereogeinity could lead to recycled materials with poor properties.

Author Contributions: E.M., M.L.M.M., R.C.-G., S.Y. and J.M.U. conceived and designed the experiments; E.M., F.R.B., M.A., G.G. and M.U.d.I.O. performed the experiments; E.M., F.R.B., M.A., D.H., M.U.d.I.O. and J.M.U. analyzed the data; M.L.M.M., R.C.-G., S.Y. and D.H. contributed with 3D printing wastes. All authors have read and agreed to the published version of the manuscript.

Acknowledgments: The authors would like to acknowledge the funding of European Union's Horizon 2020 research and innovation program under grant agreement No. 860,407 BIO-PLASTICS EUROPE; MINECOSPAIN under project CTM2017-88989-P and Universidad Politécnica de Madrid under project UPM RP 160543006. The authors also acknowledge the collaboration of the CircularizatETSII project and the coronamakers initiative.

Conflicts of Interest: The authors declare no conflict of interest.

\section{Abbreviations}

The following abbreviations are used in this manuscript:

PLA Poly(lactic acid) 


\section{References}

1. Mikula, K.; Skrzypczak, D.; Izydorczyk, G.; Warchoł, J.; Moustakas, K.; Chojnacka, K.; Witek-Krowiak, A. Environ. Sci. Pollut. Res. 2020.

2. Zhao, P.; Rao, C.; Gu, F.; Sharmin, N.; Fu, J. J. Clean. Prod. 2018, 197, 1046.

3. Choong, Y.Y.C.; Tan, H.W.; Patel, D.C.; Choong, W.T.N.; Chen, C.; Low, H.Y.; Tan, M.J.; Patel, C.D.; Chua, C.K. Nat. Rev. Mater. 2020, 5, 637.

4. Cisneros-López, E.O.; Pal, A.K.; Rodriguez, A.U.; Wu, F.; Misra, M.; Mielewski, D.F.; Kiziltas, A.; Mohanty, K.A. Mater. Today Sustain. 2020, 7-8, 100027.

5. de Andrade, M.F.C.; Souza, P.M.S.; Cavalett, O.; Morales, A.R. J. Polym. Environ. 2016, 24, 372.

6. Ong, T.K.; Choo, H.L.; Choo, W.J.; Koay, S.C.; Pang, M.M. 2020, 725.

7. Sanchez, F.A.C.; Boudaoud, H.; Hoppe, S.; Camargo, M. Addit. Manuf. 2017, $17,87$.

8. Beltrán, F.R.; Lorenzo, V.; Acosta, J.; de la Orden, M.U.; Urreaga, J.M. J. Environ. Manag. 2018, $216,25$.

9. Agüero, A.; Morcillo, D.M.; Quiles-Carrillo, L.; Balart, R.; Boronat, T.; Lascano, D.; Torres-Giner, S.; Fenollar, O. Polymers 2019, 11.

10. Peeters, B.; Kiratli, N.; Semeijn, J. J. Clean. Prod. 2019, 241, 118313.

11. Chariyachotilert, C.; Joshi, S.; Selke, S.E.M.; Auras, R. J. Plast. Film Sheeting 2012, 28, 314.

12. Castro-Aguirre, E.; Iñiguez-Franco, F.; Samsudin, H.; Fang, X.; Auras, R. Adv. Drug Deliv. Rev. 2016, 107, 333.

13. Beltrán, F.R.; Infante, C.; de la Orden, M.U.; Urreaga, J.M. J. Clean. Prod. 2019, 219, 46.

14. Carrasco, F.; Pagès, P.; Gámez-Pérez, J.; Santana, O.O.; Maspoch, M.L. Polym. Degrad. Stab. 2010, 95, 116.

Publisher's Note: MDPI stays neutral with regard to jurisdictional claims in published maps and institutional affiliations.

(C) 2020 by the authors. Submitted for possible open access publication under the terms and conditions of the Creative Commons Attribution (CC BY) license (http://creativecommons.org/licenses/by/4.0/). 